\title{
Research on food safety supervision
}

\author{
Zhenyu Lei \\ Guangdong Yangjiang quality measurement supervision and Inspection Institute, Yangjiang,Guangdong, 529500, China
}

\begin{abstract}
The quantity and quality of food additives directly affect the safety of food. Only by more scientific and accurate regulation of the use of food additives, can we eliminate a series of problems of food safety caused by the abuse of unreasonable and harmful food additives. As the first line of defense for food safety, the hygienic index of food production must be firmly controlled Good, can provide a solid guarantee for food safety management; the traceability performance of food production and circulation can better make food production run in the sun, and ensure that every link can be supervised and traceable from planting, production and processing, to consumers; strengthen the legislative supervision of food production, circulation and other links, so that food safety supervision has laws to abide by, laws to be prosecuted, and indeed guarantee Rights and interests of consumers.
\end{abstract}

safety plays a very important role.

\section{Introduction}

Food safety is related to people's livelihood, people's vegetable basket project and people's health, so we must pay absolute attention to it. As an important livelihood project, food safety must be operated safely, orderly and for a long time. How to ensure the safety of food, it is necessary to give effective supervision from planting, production and processing, sales, table and other aspects. The incidents caused by food safety have been common. There are some agricultural and sideline products that use excessive pesticides, resulting in excessive pesticide levels of agricultural products; some cultivated land and water sources are polluted by toxic chemical plants around, resulting in excessive toxic heavy metals in relevant crops; secondary pollution of food due to poor food production and processing environment; illegal addition of food Agent, etc. Therefore, it is a top priority for people's health and safety to do a good job of food safety supervision on the spot and build a "vegetable basket project" with health, safety, green and legal guarantee! It is the full guarantee of national labor force, productivity and combat effectiveness!

\section{Analysis of the importance of food safety}

\section{1 significance of food safety}

Food safety is related to the social stability of a country, the level of people's sense of security and happiness, and the security and stability of a country. Therefore, food

\section{2 food safety coverage}

Food safety includes agriculture, animal husbandry planting and breeding safety, raw material traceability, enterprise production and operation health indicators, food additive safety, food product storage and quality assurance health indicators, food circulation health indicators and other fields. Food safety runs through all aspects of our daily life. Food safety is related to the livelihood and employment of agriculture, animal husbandry and other industries. Food safety is also related to the survival and development of enterprises. More importantly, food safety is closely related to the health, safety and security index of the people.

\section{3 safety of food additives}

Food additives are closely related to daily life. Canned food and packaged food in the market circulation field are more or less added with several kinds of food additives, so is the food added with food additives really safe to eat? The answer is no, the food additives themselves are not edible, but some chemical additives added by businesses in order to increase the color, freshness and taste of food. If a large number of food additives are ingested for a long time, it will cause disease-causing injury to the body to varying degrees, or even cause cancer. At present, the relevant national food standards have clear limits on food additives. The human body will not have obvious harm when ingesting a small amount or a specified amount of food additives, but whether the limited amount is really safe after long-term

Corresponding author's e-mail:qihefu168@163.com 
accumulation and precipitation? This remains to be seen. Food additives such as essence, pigment, saccharin sodium, try to use natural ones instead of synthetic ones, so the safety will be even higher. But in order to pursue low cost, many businesses abuse synthetic food additives, so the safety of food will be greatly reduced.

\section{The correlation between the hygiene index of food production and food safety}

\section{1 scope of application of health indicators in food production}

The food safety of food processing is closely related to the whole process of food production, including the source health indicators of food raw materials, the health indicators of raw material storage, the health indicators of raw material production and processing, the health indicators of semi-finished product packaging, the health indicators of finished product storage, etc.

\section{2 possible food safety risks in food production}

\subsection{1 food safety risks brought in by food raw materials}

In order to save costs, some enterprises purchase a large number of cheap, problematic and deteriorated food raw materials, which brings food safety risks at the source of food production. In order to cover some peculiar and peculiar smell of food raw materials, enterprises add a lot of artificial flavors and pigments. What kind of food safety can be produced after such food is produced and circulated to the market?

\subsection{2 food safety risks brought by production and processing of food raw materials}

The health indicators of the working environment of food production enterprises are closely related to food safety. For example, some black workshops and small factories produce food products in extremely bad production and processing environment; some food production workers do not operate in a standard way; they do not wear uniform production clothes, production gloves and masks; food production machines are seriously polluted and are not cleaned And so on. The above-mentioned production operations will bring many unsafe factors, such as excessive bacterial content of food, secondary pollution of food raw materials and so on.

\subsection{3 food safety risks brought in by food packaging process}

In the process of food packaging operation, some production enterprises purchase poor quality packaging products based on the principle of cost priority. The cleanliness of packaging products used in food is very low, and there are many bacteria and dirt left inside. Or the use of poor quality plastic packaging products, resulting in plasticizer pollution of food and other factors will bring food safety risks in the process of food packaging.

\subsection{4 food safety risks brought in during food storage}

There should be certain requirements for the storage environment of food, and the relevant temperature and humidity should be up to standard to ensure the quality and freshness of food. But in reality, many food production enterprises do not pay attention to the environmental conditions of food storage. If the raw materials or finished products of food are stored in too humid or too high temperature environment, the food will easily deteriorate, rot or grow bacteria. Therefore, the storage of food should be operated scientifically and reasonably. 
Table 1: proportion of potential food safety risks in food production process

\title{
Proportion of potential food safety risks
}

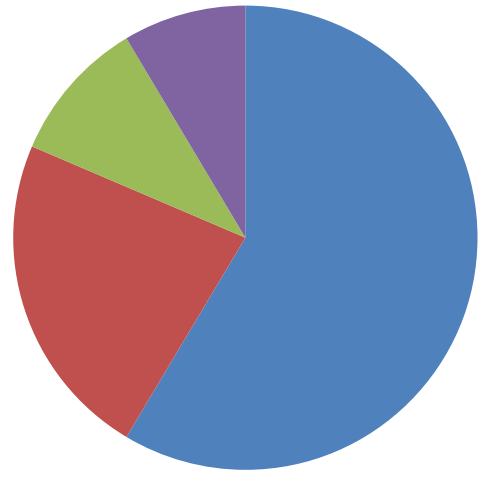

\author{
- Risks brought in by raw \\ materials \\ nisk brought in by \\ production and processing \\ - Risk brought in by food \\ packaging \\ - Risk brought in by food \\ storage
}

\section{The importance of traceability of food production and circulation in food safety supervision}

\section{1 significance of traceability of food production and circulation}

A healthy and green food can be traced back. In every link of planting and breeding, production and processing, and market circulation, not only can the whole chain of food production be transparent and sunny, but also can ensure that food production enterprises get more effective market supervision. When there is a problem food in the market, the relevant regulatory authorities can trace the responsible unit of the problem food at the first time, and quickly find and deal with the problem in any link.

\section{2 relationship between traceability of food production and circulation and food safety supervision}

Strengthening the traceability of food production and circulation is a powerful means to cut off the flow of inferior food into the market from the source, which can not only make the law enforcement of the regulatory authorities more targeted, but also enhance the effectiveness of the law enforcement of the regulatory authorities, so that each relevant link of the regulatory related food enterprises is within the scope of effective supervision, and eliminate the blind area of supervision. To ensure the safety and traceability of food quality in each link, every link of food circulation from the place of origin to the manufacturer to the market and consumers can be clearly and easily checked. The market often circulates some "three no" products, neither the manufacturer nor the product information. Once there is a quality problem in the food, it is difficult to investigate the relevant responsibility, which greatly damages the health and rights of consumers. Only by making food clear and traceable in all links of production and circulation, can all food production enterprises carry out food production and processing in open and transparent supervision and control, so as to enhance the responsibility of food production enterprises for food safety, and at the same time, improve the food safety in the market circulation field.

\section{The necessity of strengthening the legislation and supervision of food production and circulation}

\section{1 significance of legislation and supervision of food safety to market supervision}

To ensure food safety, we must have a strong legal foundation. To strengthen and improve the relevant legislation of food safety is not only to make the law enforcement and supervision agencies have laws to rely on and evidence to enforce the law, but also to provide a strong support for improving the safety monitoring of food related markets, and to make some bad businesses have no legal space to drill.

\section{2 relevant factors affecting food safety}

The purpose of strengthening and improving the formulation of food safety related laws and regulations is to eliminate some blind areas of supervision and make food safety supervision run on a long-term, stable and transparent track. At present, food safety still faces many challenges, including the following aspects:

\subsection{1 supervision is not in place and blind areas are common.}

The main reason for this phenomenon is that there is a legal blank area in food safety supervision, which makes law enforcers lose strong and powerful executive power, and also makes some bad enterprises continue to deliver 
poor quality food to the market with low production standards.

\subsection{2 food with no guarantee of quality but low price has a huge consumer market, so it will breed a batch of illegal businessmen who take risks.}

Greedy for small and cheap food is the general psychology of most small citizens. We see that low-cost food never pays attention to the health and safety of food, and blindly greedy for cheap food. We can consume these low-cost food with no guarantee of quality for a long time. With a huge consumer market, there will be a variety of supply chains, so that some food with no guarantee of quality but low price will stand firm in the market.

\subsection{3 a large number of food additives are added to packaged food and canned food, which is a huge legal factor affecting food safety.}

A superb collection of beautiful things such as days and months multiplying the chemical additives that are used in food, such as colorant, flavor, preservative, etc., are not suitable for human consumption. But as food additives, food additives are absorbed by human body. Accumulating these food additives in the body with the accumulation of daily accumulation will inevitably lead to physical changes and even carcinogenesis. And so on.

\section{Epilogue}

Strengthening and improving the legislation and supervision of food related fields is a necessary measure to ensure the safe, orderly and long-term operation of food, so that all fields related to food production can operate safely within the framework of transparency and sunshine, ensuring the food safety of the circulation market and the "vegetable basket project" of the broad masses. Let the food safety supervision have the law! If you break the law, you will be punished!

\section{Acknowledgments}

Thanks to the strong support of the affiliated units for the writing and publishing of scientific and technological papers, more writing space and conditions have been given, so that the writing and publishing of scientific and technological papers can continue and develop.

\section{References}

1. Zhao Shihui. Food safety, Tianjin Ancient Books Publishing House (2012)

2. Wang libing. Food additive safety and detection, Science Press (2011)

3. Li Hongsheng. Food circulation safety supervision and management and pragmatism, China Labor and social security press (2012)
4. Yan tingcai, Diao Enjie. Food safety and quality management, chemical industry press (2016)

5. Huangpu wild goose. Food safety management, China Quality Inspection press (2015) 